\title{
Study on nodal metastasis in neck
}

\author{
SM Mesbah Uddin Ahmad' ${ }^{1}$, AHM Zahurul Huq ${ }^{2}$, Md. Abul Hasnat Joarder ${ }^{3}$, Abrar Ahmed ${ }^{4}$, Sk. \\ Hasanur Rahman ${ }^{2}$
}

\begin{abstract}
A cross sectional study was done in ENT Department, BSMMU from October 07 to March 08. An attempt has been made to evaluate metastatic neck node clinically. 60 cases were studied. Primary lesion identified in 53 cases (88.33\%) and remain undetected in 7 cases (11.67\%). Among primary sixty (60) diseases, 43 (81.13\%) arises from upper aerodigestive tract which were squamous cell carcinoma \& $10(18.87 \%)$ came from thyroid \& parotid gland. Commonest primary site was Larynx (36.67\%). Majority (55\%) of patients were age group 41-60. Unilateral lymph node was involved in 49 cases (81.67\%), bilateral in 10 (16.67\%), contra lateral in 1 case (1.66\%), Single node in 22 (36.67\%), Multiple in 38 (63.33\%) cases. Size of the node >6cm was found in 24 cases (40\%), $3-6 \mathrm{~cm}$ in 20 cases (63.33\%), <3cm in 16 cases (26.67\%). Most of the involved nodes were in level- II.
\end{abstract}

\section{Key wards: Metastatic neck node, primary tumour}

\section{Introduction}

A malignant tumor always invades the surrounding structures. It eventually enters the channels like the lymphatics and blood vessels and group of cells are carried to the other parts where it sets up as anabolic spread, is called metastasis. ${ }^{1}$

Malignant tumours in the head and neck region have a propensity to metastasize. As the cervical region is very much rich in lymphatic supply containing 200 lymph nodes out of 500 lymph nodes in the body which may get involved in the clinical course of head \& neck malignancy. ${ }^{2}$

The tumour can metastasize in ipsilateral and/or contralateral or bilateral neck nodes. As the tumour grows within a node, it enlarges and becomes indurated and rounded. ${ }^{3}$ The tumour eventually extends though the capsule of the lymph node and invades the surrounding structures, extension through the neurovascular bundle is relatively common and results in fixation. ${ }^{4}$

One of the most important factors in head \& neck cancer is the presence or absence, level and size of

1. Registrar, ENTD, Sher-e-Bangla Medical College Hospital, Barishal.

2. Assistant Professor, ENTD, BSMMU, Dhaka.

3. Professor, ENTD, BSMMU, Dhaka.

4. Associate Professor, ENTD, Sher-e-Bangla Medical College Hospital, Barishal.

Address correspondence to: Dr. SM Mesbah Uddin Ahmed, Registrar, ENTD, Sher-e-Bangla Medical College Hospital, Barishal, Bangladesh metastatic neck disease. Many carcinomas within the head or neck will sooner or later metastasize to lymph nodes and various factors control the natural history of this event. ${ }^{5}$

Most carcinoma of the central head and neck metastasize to the lymph nodes in the deep cervical chain. ${ }^{6}$ A lymph node in the posterior triangle may represent a metastasis from the postnasal space. A secondary malignant node in the neck may also be due to a tumour below the clavicle; the lung, stomach and breast are common sites, although on occasion others can arise from a primary elsewhere in the body such as the ovary or testis. ${ }^{7}$ A cancer presenting with a node in the neck is four times more common in men than in women, with a mean age of 65 years in men and 55 years in women. ${ }^{2}$

Clinical examination still remains the most important method of assessing regional lymph nodes. Some nodes in the neck are difficult to palpate. Thus retropharyngeal and parapharyngeal nodes are almost impossible to detect by palpation until they are very large. $^{8}$

Metastatic involvement of various lymph node regions usually progress from superior to inferior in an orderly fashion, but it has been shown that in some situations lymph node groups can be bypassed even in the normal lymphogram. ${ }^{7}$

CT scanning of the neck can certainly detect metastastic lymph nodes. The three CT criteria used to define a node as metastatic or not, are size, 
peripheral enhancement and central necrosis. ${ }^{9} \mathrm{MRI}$ is at present being used in the assessment of cervical lymphadenopathy. Enlarged nodes and nodes with central necrosis are well demonstrated by MRI. Metastastic lymph nodes in the neck can be demonstrated by ultrasonogram, but distinguishing between inflammatory zand metastatic nodes is difficult. ${ }^{10}$ On occasion FNAC is helpful in demonstrating metastatic carcinoma in a lymph node. It may be helpful in the evaluation of a difficult clinical situation. For example in the assessment of a patient with an unknown primary tumour fine needle aspiration may be useful. In general, negative aspiration cytology is not sufficiently reliable and should be ignored. ${ }^{8}$

In metastatic neck disease, majority of cases have known primary sites and another portion of cases having unknown primary tumours. It is important to remember that in $90 \%$ of cases the primary tumour of a neck metastasis will be in the head and neck, and vigilant search above the clavicles will provide the primary tumour site in approximately $50 \%$ of cases. $^{2}$

In case of unknown primary, following the history and examination and more importantly radiology, the patient should be examined under a general anaesthetic which will allow the entire upper respiratory tract to be palpated; some small tumours, particularly in the tongue base and tonsil, can often better felt and seen and the nasopharynx can be carefully examined. If the tumour is discovered, a biopsy is taken and the examination completed. Often no tumour will be found and in this situation blind biopsies are taken of both sides of the nasopharynx and the tongue base and tonsillectomy performed on the side of the node. ${ }^{5}$

The prognosis for patients in whom the primary site is never discovered or in whom the primary site is not in head and neck, however is disastrous and treatment must be considered palliative. ${ }^{11}$

Data on 168 patients with a lower neck node metastasis presenting to the department of medicine, head and neck Oncology group, University of Liverpool, UK shows survival with posterior triangle metastasis is significantly better than supraclavicular metastasis. Laterality of metastasis had no effect on survival. There is no significant difference in survival between squamous and non squamous metastasis. ${ }^{12}$

\section{Aims \& Objectives}

The aims of this study were -

(1) To find out the primary sites of metastatic cervical lymph nodes.

(2) To find out the level of involvement of lymph nodes in neck.

(3) To make the nodal staging.

\section{Materials and Methods}

Type of Study: It was a cross sectional study.

Place \& period of study: In-patient department of Otolaryngology \& Head-Neck surgery of BSMMU, Dhaka from October, 2007 to March, 2008.

Sample : Sixty (60).

Inclusion criteria: Metastatic neck node with a known primary, both Squamous \& non-squamous origin in head \& neck region \& those with an unknown primary were included in this study.

Exclusion criteria: Metastatic neck node involving left supraclavicular or scalene nodes with a possible primary arising within the chest $\&$ abdomen were excluded from this study.

Data Collection :

After taking a comprehensive history every patient was subjected to a thorough physical examination with particular emphasis to ear, nose \& throat region. Neck was examined very carefully for the presence of a primary disease as well as the site, size, number \& level of lymph node involvement, their consistency \& mobility. All cases were advised for FNA biopsy of enlarged neck node. Cases revealed metastatic deposits in enlarged neck gland in FNA biopsy entered into this series.

Besides FNA biopsy of neck node, blood for TC, DC, $\mathrm{Hb} \%$, ESR, urine for R/E \& a chest X-ray P/A view were done in all cases. $X$-ray soft tissue nasopharynx lateral view, X-ray PNS - OM view, CT scan of nose \& paranasal sinuses, CT scan of larynx, CT scan of nasopharynx \& base of the skull, thyroid scan, ultrasonography of thyroid gland, thyroid function test, FNA biopsy of thyroid \& parotid swelling were done in selected cases as directed by clinical findings.

Tissue was taken from primary sites for histopathological examination for the confirmation of 
malignancy in every case. In case of growth in the nasopharynx, base of the tongue, oropharynx, larynx $\&$ pyriform fossa rigid endoscopic procedures were done under general anesthesia (G/A) \& tissue diagnosis of non squamous cell carcinoma of thyroid gland \& parotid gland was confirmed by excisional biopsy.

Those cases suspected having occult primary disease were subjected to pan-endoscopy under general anesthesia \& tissue was taken from suspected area (guided biopsy) \& sent for histopathological examination. Those with negative histopathological report and having no clinical symptoms \& signs suggestive of primary pathology based on thorough ENT \& Head - Neck examination as well as systemic examination of chest \& abdomen were taken as occult primary. CT scan of chest \& Ultrasonology of whole abdomen, Barium swallow x-ray of oesophagus, Barium meal $x$-ray of stomach, Barium follow through of small intestine, Barium enema x-ray of colon, Mammography were not possible to be done in all cases of occult primary.

\section{Observation and Results}

Table-I

Incidence of known primary \& unknown primary $(n=60)$

\begin{tabular}{lcc}
\hline Primary tumor & $\begin{array}{c}\text { Number of } \\
\text { Patients }\end{array}$ & $\begin{array}{c}\text { Percentage } \\
(\%)\end{array}$ \\
\hline Known primary & 53 & 88.33 \\
Unknown primary & 07 & 11.67 \\
\hline
\end{tabular}

The incidence of metastatic neck node with known primary is eight times more common than that of the unknown primary.

Table-II

Histopathological diagnosis of primary tumour $(n=53)$

\begin{tabular}{lcc}
\hline Type & $\begin{array}{c}\text { Number of } \\
\text { Cases }\end{array}$ & $\begin{array}{c}\text { Percentage } \\
(\%)\end{array}$ \\
\hline Squamous & 43 & 81.13 \\
Non squamous & 10 & 18.87 \\
\hline Total & 53 & 100 \\
\hline
\end{tabular}

Histopathological diagnosis of primary tumour: 43 $(81.13 \%)$ cases of metastatic neck node primary tumour arise from the surface epithelium of upper aerodigestive tract and $10(18.87 \%)$ cases from a nonsquamous origin.

Table-III

Distribution of known primary sites

\begin{tabular}{lcc}
\hline Primary site & No of Cases & Percentage (\%) \\
\hline Larynx & 22 & 36.67 \\
Pyriform fossa & 09 & 15.00 \\
Nasopharynx & 04 & 6.67 \\
Tongue & 04 & 6.67 \\
Oral cavity & 02 & 3.33 \\
Nose \& PNS & 01 & 1.67 \\
Oropharynx (Tonsil) & 01 & 1.67 \\
Thyroid gland & 08 & 13.33 \\
Parotid gland & 02 & 3.33 \\
\hline Total & 53 & 88.33 \\
\hline
\end{tabular}

Among the sq. cell carcinoma of head-neck larynx is the most common site to present with metastatic neck node followed by pyriform fossa and nasopharynx. Among the tumours of nonsquamous origin thyroid gland shows higher cervical node metastatis followed by parotid gland.

Table-IV

Age Incidence of metastatic neck node

\begin{tabular}{lcc}
\hline Age group (Years) & No of cases & Percentage (\%) \\
\hline $20-30$ & 05 & 8.33 \\
$31-40$ & 08 & 13.33 \\
$41-50$ & 19 & 31.67 \\
$51-60$ & 14 & 23.33 \\
$61-70$ & 07 & 11.67 \\
$71-80$ & 05 & 8.34 \\
$81-90$ & - & - \\
$91-100$ & 02 & 3.33 \\
\hline
\end{tabular}

The highest incidence of metastatic neck node in 4150 age group. 
Table-V

Sex distribution of metastatic neck node $(n=60)$

\begin{tabular}{lcc}
\hline Sex & No. of case & Percentage (\%) \\
\hline Male & 47 & 78.33 \\
Female & 13 & 21.67 \\
\hline
\end{tabular}

The higher incidence of metastatic neck node in males in comparison to females.

Table-VI

Accompanying symptoms on clinical presentation $(n=60)$

\begin{tabular}{llcc}
\hline No & Clinical & $\begin{array}{c}\text { No. of } \\
\text { case }\end{array}$ & $\begin{array}{c}\text { Percentage } \\
(\%)\end{array}$ \\
\hline 1 & Hoarseness of voice & 23 & 38.33 \\
2 & Respiratory distress & 08 & 13.33 \\
3 & Stirdor & 05 & 8.33 \\
4 & Dysphagia & 26 & 43.33 \\
5 & Otalgia & 05 & 8.33 \\
6 & Pain in throat & 05 & 8.33 \\
7 & Cough & 04 & 6.67 \\
8 & Hemoptysis & 02 & 3.33 \\
9 & Nasal obstruction & 05 & 8.33 \\
10 & Epistaxis & 05 & 8.33 \\
11 & Cranial nerve palsy & 07 & 11.67 \\
12 & Thyroid gland swelling & 08 & 13.33 \\
13 & Parotid gland swelling & 02 & 3.33 \\
14 & Trismas & 01 & 1.67 \\
15 & Severe headache & 03 & 5.00 \\
16 & Anorexia \& weight loss & 15 & 25.00 \\
\hline & & & \\
\hline
\end{tabular}

Besides enlarged lymph nodes, the wide range of clinical presentation reflects their primary site of origin.

\section{Table-VII}

Distribution \& status of involved lymph nodes

$$
(n=60)
$$

A

\begin{tabular}{lcc}
\hline $\begin{array}{l}\text { Distribution of } \\
\text { nodes }\end{array}$ & $\begin{array}{c}\text { No. of } \\
\text { cases }\end{array}$ & $\begin{array}{c}\text { Percentage } \\
(\%)\end{array}$ \\
\hline Unilateral & 49 & 81.67 \\
Bilateral & 10 & 16.67 \\
Contralateral & 01 & 1.66 \\
\hline
\end{tabular}

B

\begin{tabular}{lcc}
\hline $\begin{array}{l}\text { No of node } \\
\text { involvement }\end{array}$ & $\begin{array}{c}\text { No. of } \\
\text { cases }\end{array}$ & $\begin{array}{c}\text { Percentage } \\
(\%)\end{array}$ \\
\hline Single & 22 & 36.67 \\
Multiple & 38 & 63.33 \\
C & & \\
\hline Consistency & No. of & Percentage \\
\hline Hard & cases & $(\%)$ \\
Firm to hard & 32 & 53.33 \\
Firm & 24 & 40.00 \\
Soft & 03 & 5.00 \\
\hline
\end{tabular}

D

\begin{tabular}{lcc}
\hline Mobility & $\begin{array}{c}\text { No. of } \\
\text { cases }\end{array}$ & $\begin{array}{c}\text { Percentage } \\
(\%)\end{array}$ \\
\hline Mobile & 36 & 60.00 \\
Fixed & 24 & 40.00 \\
\hline
\end{tabular}

E

\begin{tabular}{lcc}
\hline $\begin{array}{l}\text { Size of lymph } \\
\text { nodes }\end{array}$ & $\begin{array}{c}\text { No. of } \\
\text { cases }\end{array}$ & $\begin{array}{c}\text { Percentage } \\
(\%)\end{array}$ \\
\hline$<3 \mathrm{~cm}$ & 16 & 26.67 \\
$3-6 \mathrm{~cm}$ & 20 & 33.33 \\
$>6 \mathrm{~cm}$ & 24 & 40.00 \\
\hline
\end{tabular}


Table-VIII

Level of lymph node involvement for each separate type of known primary.

\begin{tabular}{|c|c|c|c|}
\hline Primary site & Level of Lymph node & No. of cases & Percentage (\%) \\
\hline \multirow[t]{2}{*}{ Larynx } & Level-II & 16 & 26.67 \\
\hline & Level-II+III & 06 & 10.00 \\
\hline \multirow[t]{3}{*}{ Pyriform fossa } & Level-II+III & 02 & 03.33 \\
\hline & Level-II & 04 & 06.67 \\
\hline & Level-III & 03 & 05.00 \\
\hline \multirow[t]{2}{*}{ Nasopharynx } & Level-II & 03 & 05.00 \\
\hline & Level-II+III & 01 & 01.67 \\
\hline \multirow[t]{2}{*}{ Tongue } & Level-II & 03 & 05.00 \\
\hline & Level-I & 01 & 01.67 \\
\hline \multirow[t]{2}{*}{ Oral cavity } & Level-I & 01 & 01.67 \\
\hline & Level-III & 01 & 01.67 \\
\hline Nose \& PNS & Level-I & 01 & 01.67 \\
\hline Oropharynx (Tonsil) & Level-II & 01 & 01.67 \\
\hline \multirow[t]{2}{*}{ Thyroid gland } & Level-VI & 06 & 10.00 \\
\hline & Level-IV & 02 & 03.33 \\
\hline \multirow[t]{2}{*}{ Parotid glad } & Level-II & 01 & 01.67 \\
\hline & Level-V & 01 & 01.67 \\
\hline Total & & 53 & 88.33 \\
\hline
\end{tabular}

Showing highest lymph node involvement in level-II

Table-IXA

\begin{tabular}{lcc}
\multicolumn{3}{c}{ Staging of lymph nodes $(n=60)$} \\
\hline Stage & No. of cases & Percentage $(\%)$ \\
\hline Stage-N1 & 20 & 33.33 \\
Stage-N2 & 24 & 40.00 \\
Stage-N3 & 16 & 26.67 \\
\hline
\end{tabular}

Showing highest presentation in N2 stage.

Table IXB

Distribution of N2 nodes

\begin{tabular}{lcc}
\hline Stage & No. of cases & Percentage (\%) \\
\hline Stage-N2A & 08 & 33.33 \\
Stage-N2B & 11 & 45.83 \\
Stage-N2C & 05 & 20.83 \\
\hline
\end{tabular}

Showing highest frequency in N2B stage.
Table-X

Primary sites in bilateral neck metastases

\begin{tabular}{lcc}
\hline Primary site & No. of cases & Percentage (\%) \\
\hline Larynx & 03 & 30 \\
Thyroid gland & 02 & 20 \\
Nasopharynx & 01 & 10 \\
Base of the tongue & 01 & 10 \\
Unknown primary & 03 & 30 \\
\hline
\end{tabular}

Larynx was the commonest site in case of nodal metastasis.

\section{Discussion}

Metastatic neck disease is commonly encountered in our country. It is difficult to give an exact figure of metastasis neck disease as only few studies are available in our country and most of the studies were carried out with cervical lymphadenopathy where metastatic neck node was described as one of the commonest cause of cervical lymph node enlargement 
in adults. ${ }^{13}$ More than one third of the total body lymph nodes are distributed in the neck and certain areas of head and neck are studded with dense capillary network of lymphatics. So the rate at which neoplasm metastasize from them is very high.

An FNA biopsy of enlarged lymph node in neck showing metastatic deposit of squamous or nonsquamous origin was taken as primary selection criteria. Leveling of lymph node group was done after the Memorial Sloan Kettering Hospital (1981). Staging of lymph node group was done after AJC \& UICC (1987).

In the present series 60 cases of metastastic neck node had been studied. A Primary lesion could be identified in $53(88.33 \%)$ cases. However primary sites remained undetected in 7 (11.67\%) cases. A study in our country with the metastatic neck node shows $93.2 \%$ cases of known primary \& $6.8 \%$ cases of unknown primary sites ${ }^{14}$. However, two studies carried out abroad showed similar rate of incidence. One in the Liverpool, England showed $89.3 \%$ cases of known $\& 10.3 \%$ cases of unknown primary and another in USA revealed about $90 \%$ cases of known \& $10 \%$ cases of unknown primary ${ }^{15,16}$.

Among the primary sites $43(81.13 \%)$ cases were seen to arise from squamous lining of upper aerodigestive tract \& $10(18.87 \%)$ cases were having a nonsquamous origin arising from thyroid (13.33\%) $\&$ parotid gland $(3.33 \%)$. The study shows that metastasis from thyroid gland carcinoma is not a very uncommon entity. The incidence of metastatic neck node of thyroid origin in other series varied from $6.25 \%$ to $9.5 \%$. In the present series metastatic neck node of thyroid origin was found in $8(13.33 \%)$ cases. The higher incidence in the present series might be due to the fact that there was no selectivity for either the site of primary tumour or the histologic type.

Among the known primary sites highest incidence of metastatic neck node was found with Ca-larynx (36.66\%). All of them were located in supraglottis of larynx with either involvement of medial wall or extention into the pyriform fossa in $40 \%$ cases which may explain the high incidence of metastasis in case of supraglottic larynx. No glottic or subglottic growth was seen with neck node metastasis.

Incidence of carcinoma pyriform fossa was seen in 9 $(15 \%)$ cases. 4 (6.67\%) cases of metastatic neck node were seen to take origin from nasopharynx, 4
(6.67\%) cases from the tongue, $2(03.33 \%)$ cases from buccal mucosa, $1(1.67 \%)$ case from nose \& 1 $(1.67 \%)$ case from tonsil. Among the non-squamous origin, $8(13.33 \%)$ cases were found to arise from Cathyroid \& 2 (3.33\%) cases from Ca-parotid. The study carried out with metastatic neck node at home \& abroad show a diverse picture. In a study with metastatic neck node in the department of Otolaryngology Mount Sina Hospital \& Sunnybrook Medical center, Toronto, $40 \%$ cases were found to arise from Ca-tongue, 20\% from Ca-larynx, 20\% cases Ca-floor of mouth, $7 \%$ from Ca- tonsil, 3\% from Capalate $\& 10 \%$ from miscellaneous sites. The absence of selectivity for primary sites was the reason behind it as noted by them ${ }^{17}$. Another study with metastatic neck node in Khartoum Teaching Hospital, Sudan, most common primary site was found nasopharyn ${ }^{18}$. It might be due to their social habits and genetic predisposition. Other studies showed highest incidence of metastasis from Ca-pyriform fossa ${ }^{14}$.

Fourty-seven (78.33\%) patients were males \& 13 $(21.67 \%)$ were females with a ratio being $3.5: 1$ of ages ranging from 20 years to 96 years, which is in fair agreement with almost all the studies revealing metastatic nodes to be more frequent in males above the age of 40 . Five (8.3\%) cases presented in second decades. Three $(5 \%)$ of which took origin from carcinoma of nasopharynx, two (3.3\%) from papillary carcinoma of thyroid gland and one (1.6\%) from the carcinoma of parotid gland not at all unlikely for these sites to present with neck node in early age. In a study carried out in our country $81.85 \%$ patients were found to be male $\& 18.75 \%$ patients to be female with the ratio being 4.3:1 and all were above 40 year of age. In another study, out of 21 cases, 18 (85.71\%) patients were male \& $3(14.29 \%)$ patients were female with highest incidence in $4^{\text {th }}$ and $5^{\text {th }}$ decade. ${ }^{13}$

Calarynx (33.33\%) was found to be most common carcinoma spreading to neck node in males \& Cathyroid (6.67\%) in females. History of smoking was found to be present in $22(23.32 \%)$ males \& $8(13.33 \%)$ female patients. History of taking smoke of crude tobacco leaves was found in a 96 years old patient presented with carcinoma in pyriform fossa.

Among the presenting features, enlargement of lymph node were present in $60(100 \%)$ cases. Then, 26 (43.33\%) patients presented with dysphagia, 23 (38.33\%) cases with hoarseness of voice, 8 (13.33\%) patients with respiratory distress, 5 (8.33\%) patients 
with stridor, 5 (8.33\%) patients with otalgia, $5(8.33 \%)$ patients with pain in throat, $5(8.33 \%)$ patients with nasal obstruction, 5 (8.33\%) patients with epistaxis, $3(5 \%)$ patients with severe headache, $1(1.67 \%)$ with trismas, 7 (11.67\%) patients with cranial nerve palsy \& $7(11.67 \%)$ patients with anorexia \& weight loss. $8(13.33 \%)$ patients presented with thyroid swelling \& 2 (3.33\%) patients with parotid gland swelling. These finding are with the findings of other published series. ${ }^{13}$

The disease was unilateral in 49 (81.67\%) cases, bilateral in $10(16.67 \%)$ cases \& contralateral in 1 (1.66)\% case of carcinoma of larynx. This is supported by other works done with metastatic neck disease in our country with high incidence of unilateral metastatic neck node. ${ }^{13}$ In a work on metastatic neck disease done by G. B snow and his team in Netherland Cancer Institute, Amsterdam, ipsilateral enlargement of lymph node demonstrated in $87 \%$ cases. That work also showed bilateral enlargement in $8.6 \%$ \& contralateral enlargement in $3.6 \%$ cases.

Lymph node involved was single in 22 (36.6\%) patients \& multiple in $38(63.33 \%)$ cases. G.B. Snow \& his team of Netherland Cancer Hospital, Amsterdam got $61.3 \%$ cases of single node enlargement \& $38.7 \%$ cases of multiple lymph node enlargement in their series. The other studies carried out in our country lymph node enlargement were solitary in $52.4 \%$ $62.5 \%$ cases \& multiple in $37.5 \%-47.6 \%$ cases. ${ }^{13}$ This picture is not consistent with the findings of present study, which might be due to more inclusion of metastatic neck node in advanced stage.

In this study, nodes were found less than $3 \mathrm{~cm}$ in 16 (26.67\%) cases, 3 to $6 \mathrm{~cm}$ in $20(33.33 \%)$ cases \& more than $6 \mathrm{~cm}$ in $24(40 \%)$ cases. But one study showed enlarged lymph node $<3 \mathrm{~cm}$ in $85 \%$ cases \& $>3 \mathrm{~cm}$ in size in $15 \%$ cases only. This indicates more late presentation of patients of our country, which corresponds with the ignorance, illiteracy \& poor socio-economic status of our people.

Lymph nodes were hard in 32 (53.33\%) cases, firm to hard in $24(40 \%)$ cases, firm in $03(5 \%)$ cases \& soft in $1(1.67 \%)$ cases. In other studies hard \& firm to hard lymph nodes were found in $87.5 \%$ to $90.5 \%$ cases \& firm lymph node in $9.5 \%$ to $12.5 \%$ cases.

In $36(60 \%)$ cases lymph nodes were found mobile \& 24 (40\%) cases were found fixed. Mobility of the node varied from $57 \%$ to $60 \%$ \& fixity from $43 \%$ to $40 \%$ in a study carried out in Bangladesh ${ }^{9}$. In other study, fixity of nodes varied from $16.4 \%$ to $29.6 \%$ representing their early presentation once again.

While leveling of the lymph node, most commonly involved lymph node region was found to be level II (40\%) followed by level II + III (30\%). This is in agreement with most studies that the upper jugular lymph node chain is most commonly involved with head \& neck nodal metastasis ${ }^{18}$.

The higher incidence of $\mathrm{N} 2$ stage of lymph node in our series is well reported by other Bangladeshi series. ${ }^{5}$

\section{Conclusion}

Data presented in this study may considerably vary with any large series but since then since the cases were collected very carefully over a period of six months from a hospital of national reference level, the study might be of some credential reflecting certain facts. Though inflammatory neck disease is very common in our country, one should not forget the possibility of metastatic carcinoma in an adult presenting with a rapidly growing, hard, non-tender, lateral neck mass. While enlarged cervical node in an elderly patient should always be considered as metastatic until proved otherwise. Because delay in the diagnosis will eliminate the best opportunity for effective treatment with curative inten.

\section{References}

1. Islam A, Alam MM, Hadi HIA, Detection of Metastatic Cervical Lymph node. Bangladesh Journal of Otorhinolaryngology, 2005; 11(1/2): 2532.

2. Watkinson JC, Gaze MN, Wilson JA, Metastatic neck disease. In: Stell \& Maran's Head \& neck Surgery, Butterworth Heinemann, Oxford: $4^{\text {th }}$ edition; 2000, Chap. 12: pp. 197-214.

3. Bruce R. In: Donoff manual of oral and maxillofacial surgery, $3^{\text {rd }}$ edition, Mosby 1997; 325.

4. Saha JP. In: Head neck surgery. $2^{\text {nd }}$ edition, London. Churchill Livingstone, 1996; 355.

5. Shah JP. Cervical lymph node metastasis, its diagnostic, therapeutic and prognostic implications. Oncology, 1990; 4: 61-9.

6. Shah J. Cervical lymph nodes in Head and Neck surgery, $2^{\text {nd }}$ edition, Mosby-Wolfe, London, 1996; 355-92. 
7. Fisch UP, Sigel ME. Cervical lymphatic systems as visualized by lymphography. Annals of Otology, Rhinology and Laryngology, 1964; 73:870-82.

8. Hibbert J, Metastatic neck disease. In: ScottBrown's Otolaryngology, Butterworth Heinemann, Oxford: $6^{\text {th }}$ edition, vol. 5: pp. 5/17/ 1-5/17/15.

9. Martin H, Romieu C. Cervical lymph node metastasis as the first symptom of cancer, Surg.Gynaecol obstet, 78:133.

10. Schuller DE, Mcgirt WF and others. The prognostic significance of metastatic cervical lymph nodes. Laryngoscope, 1980; 90: 557-70.

11. Jones AS, Cook JA, Phillips DE, Roland NR. Squamous carcinoma presenting as an enlarged cervical lymph node. Cancer, 1993; Sep 1; 72(5): 1756-61.

12. Giridharan W. Hughes J, Fenton JE. Lymph node metastasis in the lower neck. Clin Otolaryngol Allied Sci, 2003; 28(3): 221-6.
13. Hadi HIA, Cervical lymphadenopathy- A Clinicopathological Study of 100 cases (Dissertation BCPS) 2000.

14. Sako K. Fallibility of palpation in diagnosis of metastasis to nodes; surg. Gyneacol obstet, 1964; 118: (989).

15. Walter J.B. \& Israel M.S. Spread of Malignant tumours. In General Pathology, $4^{\text {th }}$ ed. London. Churcill Livingstone, 1974; p365-373.

16. Spiro RH and others : cervical node metastatis from epidermoid carcinoma of the oral cavity \& oropharynx, Am J surg, 1974; 128: 562.

17. Ali S, Tiwari RM, Snow GB. False positive \& false negative neck nodes. Head Neck surgery, 1985; 8: 78-82.

18. Lefebvre JL, Conche-Dequeant B, Van JT et al. Cervical Lymph nodes from an unjnown tumour, Am J Surg, 1990; 160: 443-456. 